\title{
Children's and parents' perceptions of the determinants of children's fruit and vegetable intake in a low-intake population
}

\author{
Asa Gudrun Kristiansdottir ${ }^{1}$, Ilse De Bourdeaudhuij ${ }^{2}$, Knut-Inge Klepp ${ }^{3}$ and \\ Inga Thorsdottir ${ }^{1, *}$ \\ 'Unit for Nutrition Research, Landspitali-University Hospital and Faculty of Food Science and Human Nutrition, \\ University of Iceland, Reykiavik, Iceland: ${ }^{2}$ Department of Movement and Sport Sciences, Ghent University, \\ Ghent, Belgium: ${ }^{3}$ Department of Nutrition, University of Oslo, Oslo, Norway
}

Submitted 19 December 2007: Accepted 28 October 2008: First published online 16 February 2009

\begin{abstract}
Objective: To study the differences between children's self-reports and parents' reports on environmental determinants of fruit and vegetable intake among 11year-old children in the European country with the lowest reported consumption. A second objective was to examine the observed variance in fruit and vegetable intake among the children.

Design: A cross-sectional survey was performed in Iceland as a part of the Pro Children cross-Europe survey. Children's usual fruit and vegetable intake and its determinants were assessed through self-reports from the children ( $n$ 963) and their parents' reports.

Results: Children reported lower availability and accessibility of fruits at home than did their parents, while the reports of children and parents for vegetables were more in agreement. A larger proportion of the observed variance in children's fruit and vegetable intake could be explained by the child's perception than by the parent's perception of determinants. The strongest determinants for fruit and vegetable intake according to the children's reports were availability at home, modelling, demanding family rule and knowledge of recommendations. The strongest modelling determinant for fruit was the father's fruit intake while for vegetables it was eating vegetables together with the family.

Conclusion: Eleven-year-old children should be asked themselves what determines their fruit and vegetable intake. However, children reported determinants in the physical and social environment, of which the parents are a part, as an important determinant for their intake. Interventions aiming to increase fruit and vegetable intake among children must therefore target the parents.
\end{abstract}

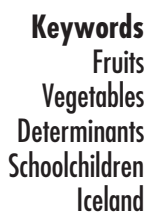

Epidemiological evidence suggests that regular fruit and vegetable intake helps to promote health and prevent chronic disease ${ }^{(1-3)}$. The health benefits of fruits and vegetables seen in epidemiological studies are the main reason for the recommended intake of at least $400 \mathrm{~g}$ of fruits and vegetables per day ${ }^{(4)}$. However, large population groups, particularly in northern Europe, eat far less than the recommended amount of fruits and vegetables.

The present study is a part of the Pro Children crossEurope survey, involving nine European countries. The survey aims to assess fruit and vegetable consumption among 11-year-old schoolchildren and their parents, and to elucidate the potential determinants of consumption at the individual, social and environmental level ${ }^{(5,6)}$. Knowing the determinants of behaviour is necessary to develop an intervention. Insight into the determinants of fruit and vegetable consumption where intake is low can possibly be used to increase intake in low-intake population groups. An intervention aimed at increasing fruit and vegetable intake among children is likely to maximize health benefits, as healthy food habits acquired in childhood tend to continue into adulthood ${ }^{(7)}$ and children are more apt to change their food habits than adults $^{(8,9)}$. Parents are determinants of the environment for young children; parent's behaviour has therefore been an obvious area for attention ${ }^{(9-12)}$. There are, however, only a few studies assessing child-parent agreement of the determinants of children's food intake, especially their fruit and vegetable intake: a Norwegian study and two Dutch studies ${ }^{(13-15)}$. In the Pro Children cross-Europe survey, children and parents were asked parallel questions on the environmental determinants of fruit and vegetable intake, making it possible to study differences in perception. 
The results from the Pro Children cross-Europe survey showed that fruit and vegetable intake among children was lowest in Iceland ${ }^{(16)}$. Sixty-four per cent of Icelandic children ate fruit less than once per day, and $61 \%$ ate vegetables less than once per day. Fruit and vegetable intake among mothers in Iceland was low ${ }^{(17)}$. Determinants of fruit and vegetable intake, based on children's self-reports, have been studied. Respectively, 31\% and $39 \%$ of the variance in children's fruit intake and vegetable intake was explained by the determinants studied ${ }^{(18)}$. The major environmental determinants were availability at home, which was positively related to both fruit and vegetable intake, as was modelling and demand family rule, while active encouragement was negatively related to intake. Self-efficacy was the strongest personal determinant of fruit intake, followed by knowledge of recommendations, attitudes, preferences and liking. For vegetable intake, preferences and liking were the strongest personal determinants, followed by knowledge of recommendations and self-efficacy.

The present study focuses on determinants in the physical and the social environment, of which the parents are part, and which in turn influence the more proximal determinants found at the personal level. The objective of the present study was to study differences between children's self-reports and parents' reports on the physical and social environmental determinants of fruit and vegetable intake of children in Iceland. A second objective was to examine the observed variance in fruit and vegetable intake among the children.

\section{Methods}

\section{Sample and procedure}

A cross-sectional survey was performed in Iceland (in the autumn of 2003) as part of the Pro Children cross-Europe survey. A random national sample of thirty-three primary schools was selected from a list from Statistics Iceland. Research approval was obtained from the Icelandic Data Protection Authority. Approval to contact the schools was obtained from the Reykjavik School District Head Office and Service Centre. The headmasters of the schools were approached about their willingness to participate (thirtytwo schools participated), and the class teachers were asked to collect the data using standardized instructions. Children in the sixth grade (born 1992) answered a selfadministered questionnaire, with instructions and help from the teacher. The children were sent home with questionnaires for their parents. A total of 1235 children, and 981 parents, returned the questionnaire. All children and their parents received written information on the project. The parent-child pairs were identified through labelling of the otherwise anonymous questionnaires. The final sample consisted of 963 child-parent couples, 480 girls and 483 boys, 819 mothers and 93 fathers; fifty-one did not answer the question on the relationship to the child, or had a different relationship to the child other than being its mother or father.

Parents were asked about his/her and his/her partner's education and occupation. These answers were used as an approximate measure of the family's socio-economic status (SES), using the higher SES for the family. These answers were coded into five categories according to a standardized protocol with national adaptation, using the occupation-status list from Statistics Iceland (ISTARF 95).

\section{Instrument}

Self-administered questionnaires were developed for children and their parents to assess fruit and vegetable intake and identify the determinants of their fruit and vegetable intake. The dietary part of the questionnaire consisted of an FFQ with four questions on usual intake of fresh fruits, salad or grated vegetables, other raw vegetables and cooked vegetables. The answer categories ranged from never to more than twice per day on an 8-point scale. This dietary assessment showed high reliability and validity. The results have been presented elsewhere ${ }^{(19,20)}$.

An overview of the variables assessed, and the children's and parents' questions on determinants of fruit and vegetable consumption, is presented in Table 1 . The determinant parts of the questionnaires and their reliability and validity have been presented elsewhere ${ }^{(21)}$.

\section{Statistical analyses}

The data were analysed using the SPSS statistical software package version 11 (SPSS Inc., Chicago, IL, USA). Repeated-measures ANOVA were executed with perception (child-parent) as the within-subject factor and the gender of the child (boy-girl) as the between-subjects factor for each of the variables. The main effect of perception shows whether there are significant differences between the perceptions of the child and the parent; the main effect of gender shows whether there are differences in perceptions between boys and girls (combining responses of parents and children); and the interaction effect shows whether the differences in perceptions between children and parents depend on the gender of the child. The significance level was set at $P<0 \cdot 01$. The study had power to detect a difference of 0.25 points, on a 5 -point scale, at $88.8 \%$ power. Hierarchical regression analyses were performed to determine the explained variance of the children's fruit and vegetable intake.

\section{Results}

The correlation coefficients between a child's and its parent's fruit and vegetable intake, based on the FFQ, were low. For fruit the correlation coefficient was $0 \cdot 21$ $(P<0 \cdot 01)$, for vegetables $0 \cdot 17(P<0 \cdot 02)$ and for fruit and vegetables combined $0 \cdot 24(P<0 \cdot 01)$. 
Table 1 Children's and parents' questions on the determinants of fruit and vegetable intake, an overview of the variables assessed. Parallel questions were asked on fruits $(F)$ and vegetables $(V)$; the labels on the response scales were similar for children and parents

\begin{tabular}{|c|c|c|}
\hline Variable & Child's question & Parent's question \\
\hline $\begin{array}{l}\text { Availability at home (different } \\
\text { kinds of } F / V \text { ) }\end{array}$ & $\begin{array}{l}\text { Are there usually different kinds of } F / V \text { available } \\
\text { at home? }{ }^{1}\end{array}$ & $\begin{array}{l}\text { How often do you have different kinds of F/V } \\
\text { available at home? }^{1}\end{array}$ \\
\hline Availability of specific F/V & $\begin{array}{l}\text { If you mention at home what F/V you would like } \\
\text { to eat, will they be bought? }\end{array}$ & $\begin{array}{l}\text { How often do you buy specific F/V because your } \\
\text { child asks for them? }\end{array}$ \\
\hline Accessibility at home & $\begin{array}{l}\text { Does your mother or father usually cut up F/V } \\
\text { for you? }\end{array}$ & $\begin{array}{l}\text { How often do you cut up F/V for your child to eat } \\
\text { between meals? }\end{array}$ \\
\hline Modelling & My mother/father eats F/V every day ${ }^{2}$ & Eating $F / V$ every day is a habit for $m e^{2}$ \\
\hline $\begin{array}{l}\text { Modelling (eat vegetables } \\
\text { together) }\end{array}$ & $\begin{array}{l}\text { I often eat vegetables together with my } \\
\text { family }^{2}\end{array}$ & $\begin{array}{l}\text { How often do you eat vegetables together with } \\
\text { your child? }\end{array}$ \\
\hline Active encouragement & $\begin{array}{l}\text { My mother/father encourages me to eat F/V } \\
\text { every day }{ }^{2}\end{array}$ & Do you have to persuade your child to eat $F / V ?^{3}$ \\
\hline Demand family rule & Do your parents tell you to eat $F / V$ every day? ${ }^{1}$ & How often do you oblige your child to eat F/V? ${ }^{1}$ \\
\hline Allow family rule & $\begin{array}{l}\text { Are you allowed to eat as much F/V as you } \\
\text { like? }\end{array}$ & $\begin{array}{l}\text { How often do you allow your child to eat as } \\
\text { much } \mathrm{F} / \mathrm{V} \text { as he/she likes? }\end{array}$ \\
\hline Self-rated intake & Do you think that you eat much or little F/V? ${ }^{4}$ & Do you think that your child eats enough F/V? \\
\hline Habit & To eat $F / V$ every day is a habit for $\mathrm{me}^{2}$ & Eating $F / V$ every day is a habit for my child ${ }^{2}$ \\
\hline $\begin{array}{l}\text { Knowledge of } \\
\text { recommendations }\end{array}$ & How much F/V do you think you should eat? ${ }^{6}$ & $\begin{array}{l}\text { How much F/N should be included in a healthy } \\
\text { diet for children, aged } 10-12 \text { years? }\end{array}$ \\
\hline
\end{tabular}

The labels on the question were as follows. 1: Yes, always; Yes, most days/often; Sometimes; Seldom; Never. 2: I fully agree; I agree somewhat; Neither agree nor disagree; I disagree somewhat; I fully disagree. 3: Yes, he/she never eats F/V unprompted; Yes, sometimes; Almost never; No, he/she eats F/V often unprompted. 4: Very many F/V; Many F/V; Not many, not few; Few F/V; Very few F/V. 5: Yes, definitely; Yes, probably; No, probably not; No, definitely not. 6: No F/V; 1-3 times/week; 4-6 times/week; 1 time/d; 2 times/d; 3 times/d; 4 times/d; 5 times or more/d (re-coded to $<2$ times/d (0) or 2 times or more/d (1)).

\section{Children's and parents' perceptions - fruit}

Differences were found between children's and parents' reports for most of the determinants of fruit intake (Table 2). Parents reported more positively on availability and accessibility of fruits at home than did their children. Children reported more modelling, more active encouragement, more demand and considered eating fruit every day more a habit than their parents. Girls and their parents reported more positively on availability of specific fruits than did boys and their parents. In addition, boys and their parents rated their fruit intake as lower and also reported fruit intake to be less a habit than did girls and their parents. Parents of boys reported more encouragement and demand than parents of girls, while boys and girls reported similar encouragement and demands to eat fruit from their parents.

\section{Children's and parents' perceptions - vegetables}

Differences between children's and their parents' reports were found for most of the determinants of vegetable intake (Table 3). Children reported more positively on availability of specific vegetables than their parents. Children reported more active encouragement and more demands to eat vegetables than did their parents; children rated their vegetable intake as greater and reported the recommendation more accurately than their parents. Parents reported more positively that their children were allowed to eat vegetables as much as they liked. Girls and their parents rated their intake greater than did boys and their parents. Girls reported eating vegetables more often with their family than did boys, girls also reported more allowing rules, while the parents of girls and boys reported similarly on these determinants. Mothers of boys reported more encouragement than mothers of girls, while girls and boys reported similar encouragement.

\section{Hierarchical regression model - fruit}

Parents' reports of the assessed determinants did not explain the variance in children's fruit intake as strongly as the children's own reports, $9 \%$ and $18 \%$, respectively (Tables 4 and 5). When looking at the parents' reports, availability at home and accessibility were positively related to children's fruit intake but became non-significant in later steps of the model. Active encouragement was negatively related to intake. When looking at the children's reports, gender was significant but became non-significant in later steps of the model. The availability at home reported by the children was positively related to fruit intake. Modelling of fathers (i.e. father eats fruit every day) and demanding family rule were both positively related to fruit intake. Children's knowledge of recommendations was also positively related to fruit intake.

\section{Hierarchical regression model - vegetables}

In general, the model explained more variance in vegetable than fruit intake, as with fruit intake more variance was explained by the children's own reports than the parent's. The variables assessed among parents explained 16\% of the variance of children's vegetable intake (Table 6). The effect of gender and SES of the family were significant, with girls eating more vegetables than boys and children in families of high SES eating more vegetables than children in families of lower SES. Accessibility was positively related to children's vegetable intake but became nonsignificant in later steps of the model. Active encouragement 

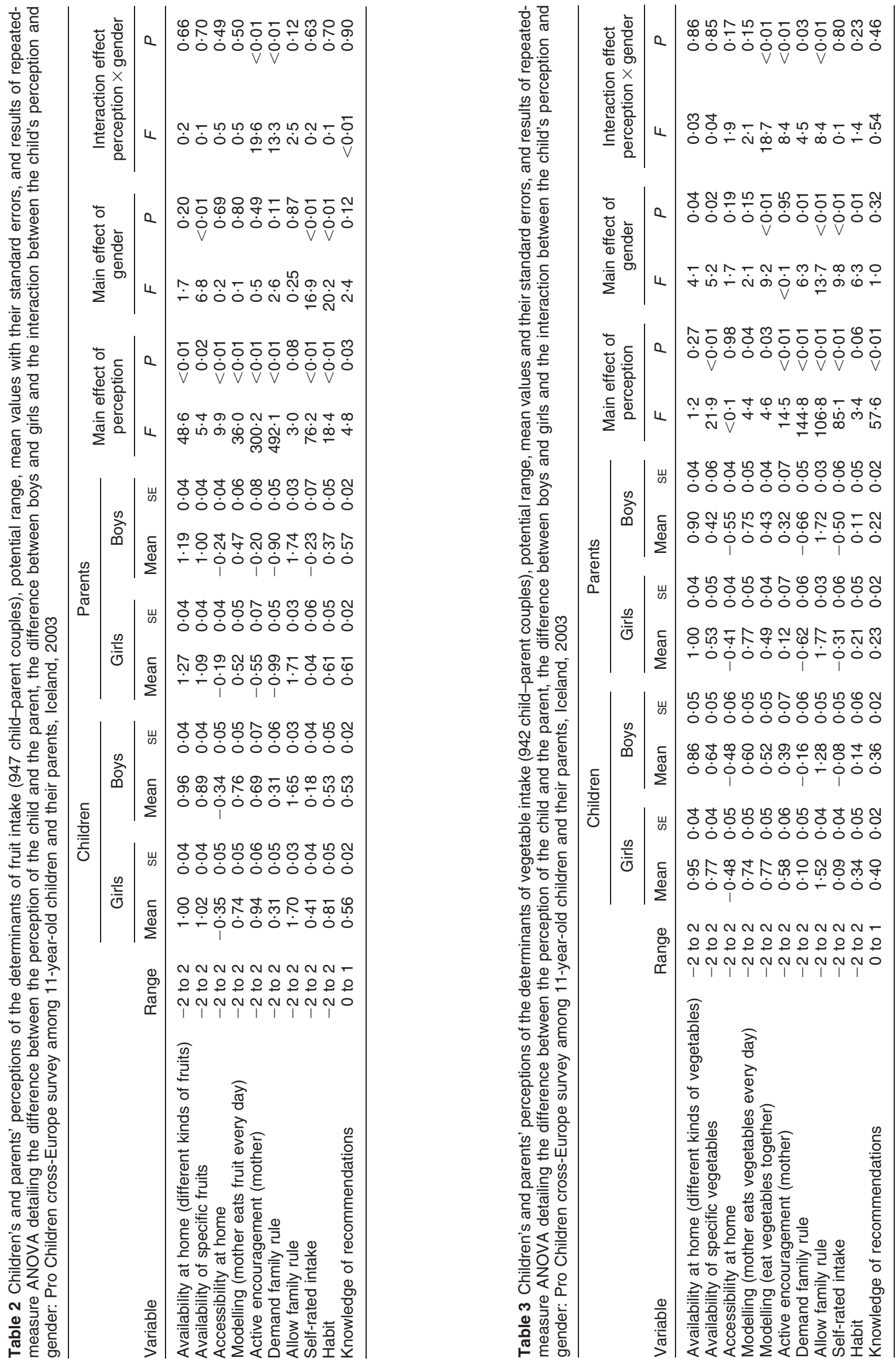
Table 4 Hierarchical regression model explaining the variance in children's fruit intake, parents' questionnaire ( $n$ 697): Pro Children crossEurope survey among 11-year-old children and their parents, Iceland, 2003

\begin{tabular}{|c|c|c|c|c|c|c|c|c|}
\hline \multirow[b]{2}{*}{ Variable } & \multicolumn{2}{|c|}{ Step 1} & \multicolumn{2}{|c|}{ Step 2} & \multicolumn{2}{|c|}{ Step 3} & \multicolumn{2}{|c|}{ Step 4} \\
\hline & $\beta$ & $P$ & $\beta$ & $P$ & $\beta$ & $P$ & $\beta$ & $P$ \\
\hline \multicolumn{9}{|l|}{ Background variables } \\
\hline Gender & 0.08 & 0.04 & 0.07 & $0 \cdot 07$ & $0 \cdot 04$ & $0 \cdot 30$ & 0.03 & $0 \cdot 36$ \\
\hline Residence & -0.02 & $0 \cdot 52$ & -0.02 & $0 \cdot 64$ & 0.01 & $0 \cdot 76$ & 0.02 & 0.69 \\
\hline Family SES & 0.06 & $0 \cdot 15$ & 0.03 & $0 \cdot 37$ & 0.05 & $0 \cdot 22$ & 0.04 & $0 \cdot 23$ \\
\hline \multicolumn{9}{|l|}{ Physical-environmental } \\
\hline Availability at home (different kinds of fruits) & & & $0 \cdot 10$ & $<0.01$ & 0.05 & $0 \cdot 19$ & 0.04 & $0 \cdot 31$ \\
\hline Availability of specific fruits & & & 0.03 & $0 \cdot 72$ & 0.04 & $0 \cdot 29$ & 0.04 & $0 \cdot 26$ \\
\hline Accessibility at home (cut up fruits to eat between meals) & & & $0 \cdot 12$ & $<0.01$ & 0.08 & 0.05 & 0.08 & 0.06 \\
\hline \multicolumn{9}{|l|}{ Socio-environmental } \\
\hline Modelling (mother eats fruit every day) & & & & & 0.09 & $0 \cdot 02$ & 0.08 & 0.04 \\
\hline Modelling (eat fruits together) & & & & & -0.01 & 0.87 & -0.01 & 0.85 \\
\hline Active encouragement (mother) & & & & & -0.23 & $<0.01$ & $-0 \cdot 22$ & $<0.01$ \\
\hline Demand family rule & & & & & 0.03 & 0.50 & 0.02 & 0.56 \\
\hline Allow family rule & & & & & -0.02 & 0.50 & -0.02 & 0.55 \\
\hline \multicolumn{9}{|l|}{ Personal } \\
\hline Knowledge & & & & & & & 0.07 & $0 \cdot 08$ \\
\hline Adjusted $R^{2}$ & 0.005 & & 0.036 & & 0.085 & & 0.088 & \\
\hline$R^{2}$ change & 0.009 & $0 \cdot 10$ & 0.035 & $<0.01$ & 0.055 & $<0.01$ & 0.004 & 0.08 \\
\hline
\end{tabular}

SES, socio-economic status.

Table 5 Hierarchical regression model explaining the variance in children's fruit intake, child's questionnaire ( $n$ 745): Pro Children crossEurope survey among 11-year-old children and their parents, Iceland, 2003

\begin{tabular}{|c|c|c|c|c|c|c|c|c|}
\hline \multirow[b]{2}{*}{ Variable } & \multicolumn{2}{|c|}{ Step 1} & \multicolumn{2}{|c|}{ Step 2} & \multicolumn{2}{|c|}{ Step 3} & \multicolumn{2}{|c|}{ Step 4} \\
\hline & $\beta$ & $P$ & $\beta$ & $P$ & $\beta$ & $P$ & $\beta$ & $P$ \\
\hline \multicolumn{9}{|l|}{ Background variables } \\
\hline Gender & $0 \cdot 10$ & $<0.01$ & $0 \cdot 10$ & $<0.01$ & 0.08 & 0.03 & 0.07 & 0.04 \\
\hline Residence & $-0 \cdot 01$ & $0 \cdot 70$ & -0.02 & 0.59 & -0.01 & $0 \cdot 70$ & -0.02 & 0.63 \\
\hline Family SES & 0.06 & $0 \cdot 10$ & 0.03 & 0.44 & 0.02 & 0.55 & 0.02 & 0.54 \\
\hline \multicolumn{9}{|l|}{ Physical-environmental } \\
\hline Availability at home (different kinds of fruits) & & & $0 \cdot 21$ & $<0.01$ & $0 \cdot 17$ & $<0.01$ & $0 \cdot 16$ & $<0.01$ \\
\hline Availability of specific fruits & & & 0.01 & 0.84 & -0.02 & 0.65 & -0.02 & 0.54 \\
\hline Accessibility at home (cut up fruits to eat between meals) & & & 0.05 & 0.21 & $<0.01$ & 0.98 & 0.01 & 0.74 \\
\hline \multicolumn{9}{|l|}{ Socio-environmental } \\
\hline Modelling (mother eats fruit every day) & & & & & 0.07 & $0 \cdot 13$ & 0.04 & $0 \cdot 31$ \\
\hline Modelling (father eats fruit every day) & & & & & $0 \cdot 14$ & $<0.01$ & $0 \cdot 14$ & $<0.01$ \\
\hline Modelling (friend eats fruit every day) & & & & & 0.03 & 0.42 & $<0.01$ & 0.97 \\
\hline Active encouragement (mother) & & & & & -0.07 & 0.22 & -0.06 & 0.31 \\
\hline Active encouragement (father) & & & & & -0.05 & $0 \cdot 36$ & -0.05 & 0.33 \\
\hline Demand family rule & & & & & $0 \cdot 16$ & $<0.01$ & $0 \cdot 13$ & $<0.01$ \\
\hline Allow family rule & & & & & 0.04 & 0.28 & 0.03 & 0.47 \\
\hline \multicolumn{9}{|l|}{ Personal } \\
\hline Knowledge & & & & & & & $0 \cdot 28$ & $<0.01$ \\
\hline Adjusted $R^{2}$ & $0 \cdot 010$ & & 0.056 & & $0 \cdot 104$ & & $0 \cdot 182$ & \\
\hline$R^{2}$ change & 0.014 & 0.01 & 0.049 & $<0.01$ & 0.056 & $<0.01$ & 0.077 & $<0.01$ \\
\hline
\end{tabular}

SES, socio-economic status.

was negatively related to intake. When looking at the children's reports, the regression model explained $37 \%$ of children's vegetable intake (Table 7). The effect of gender and SES of the family were significant, with girls eating more vegetables than boys and children in families of high SES eating more vegetables than children in families of low SES. The availability at home was positively related to vegetable intake. Eating vegetables together and demanding family rule were both positively related to vegetable intake. Children's knowledge of recommendations was also positively related to vegetable intake.

\section{Discussion}

Differences were found between children's self-reports and parents' reports on the environmental determinants of fruit and vegetable intake of the children in the Icelandic part of the Pro Children survey. A larger proportion of the observed variance in children's fruit and vegetable intake could be explained by the children's reports than by the parent's. The strongest determinants for fruit and vegetable intake according to the children's reports were availability at home, modelling, demanding family rule 
Table 6 Hierarchical regression model explaining the variance in children's vegetable intake, parents' questionnaire ( $n$ 664): Pro Children cross-Europe survey among 11-year-old children and their parents, Iceland, 2003

\begin{tabular}{|c|c|c|c|c|c|c|c|c|}
\hline \multirow[b]{2}{*}{ Variable } & \multicolumn{2}{|c|}{ Step 1} & \multicolumn{2}{|c|}{ Step 2} & \multicolumn{2}{|c|}{ Step 3} & \multicolumn{2}{|c|}{ Step 4} \\
\hline & $\beta$ & $P$ & $\beta$ & $P$ & $\beta$ & $P$ & $\beta$ & $P$ \\
\hline \multicolumn{9}{|l|}{ Background variables } \\
\hline Gender & $0 \cdot 17$ & $<0.01$ & $0 \cdot 16$ & $<0.01$ & $0 \cdot 15$ & $<0.01$ & $0 \cdot 15$ & $<0.01$ \\
\hline Residence & $0 \cdot 10$ & 0.01 & $0 \cdot 10$ & 0.01 & 0.08 & 0.03 & 0.08 & 0.02 \\
\hline Family SES & $0 \cdot 16$ & $<0.01$ & $0 \cdot 13$ & $<0.01$ & $0 \cdot 12$ & $<0.01$ & $0 \cdot 12$ & $<0.01$ \\
\hline \multicolumn{9}{|l|}{ Physical-environmental } \\
\hline Availability at home (different kinds of vegetables) & & & 0.06 & $0 \cdot 10$ & 0.03 & 0.44 & 0.03 & 0.47 \\
\hline Availability of specific vegetables & & & 0.06 & $0 \cdot 17$ & -0.03 & 0.49 & -0.03 & 0.44 \\
\hline Accessibility at home (cut up vegetables to eat between meals) & & & $0 \cdot 13$ & $<0.01$ & 0.04 & $0 \cdot 31$ & 0.04 & $0 \cdot 31$ \\
\hline \multicolumn{9}{|l|}{ Socio-environmental } \\
\hline Modelling (mother eats vegetables every day) & & & & & 0.08 & 0.07 & 0.07 & $0 \cdot 12$ \\
\hline Modelling (eat vegetables together) & & & & & $0 \cdot 10$ & 0.02 & $0 \cdot 10$ & 0.02 \\
\hline Active encouragement (mother) & & & & & -0.21 & $<0.01$ & $-0 \cdot 21$ & $<0.01$ \\
\hline Demand family rule & & & & & $-0 \cdot 01$ & $0 \cdot 78$ & -0.02 & 0.68 \\
\hline Make your child eat all vegetables with his/her meal & & & & & 0.01 & $0 \cdot 74$ & 0.01 & 0.76 \\
\hline Make your child eat part of the vegetables with his/her meal & & & & & 0.07 & 0.08 & 0.07 & 0.09 \\
\hline Make your child eat some of the vegetables with his/her meal & & & & & 0.08 & 0.07 & 0.08 & 0.06 \\
\hline Allow family rule & & & & & $<0.01$ & 0.91 & $<0.01$ & 0.90 \\
\hline \multicolumn{9}{|l|}{ Personal } \\
\hline Knowledge & & & & & & & $0 \cdot 06$ & $0 \cdot 11$ \\
\hline Adjusted $R^{2}$ & 0.064 & & 0.094 & & $0 \cdot 163$ & & 0.165 & \\
\hline$R^{2}$ change & 0.068 & $<0.01$ & 0.034 & $<0.01$ & 0.079 & $<0.01$ & 0.003 & $0 \cdot 11$ \\
\hline
\end{tabular}

SES, socio-economic status.

Table 7 Hierarchical regression model explaining the variance in children's vegetable intake, child's questionnaire $(n 770)$ : Pro Children cross-Europe survey among 11-year-old children and their parents, Iceland, 2003

\begin{tabular}{|c|c|c|c|c|c|c|c|c|}
\hline \multirow[b]{2}{*}{ Variable } & \multicolumn{2}{|c|}{ Step 1} & \multicolumn{2}{|c|}{ Step 2} & \multicolumn{2}{|c|}{ Step 3} & \multicolumn{2}{|c|}{ Step 4} \\
\hline & $\beta$ & $P$ & $\beta$ & $P$ & $\beta$ & $P$ & $\beta$ & $P$ \\
\hline \multicolumn{9}{|l|}{ Background variables } \\
\hline Gender & $0 \cdot 20$ & $<0.01$ & $0 \cdot 20$ & $<0.01$ & $0 \cdot 15$ & $<0.01$ & $0 \cdot 15$ & $<0.01$ \\
\hline Residence & 0.07 & 0.06 & 0.03 & 0.44 & 0.02 & 0.49 & 0.02 & 0.48 \\
\hline Family SES & $0 \cdot 19$ & $<0.01$ & $0 \cdot 16$ & $<0.01$ & $0 \cdot 13$ & $<0.01$ & $0 \cdot 13$ & $<0.01$ \\
\hline \multicolumn{9}{|l|}{ Physical-environmental } \\
\hline Availability at home (different kinds of vegetables) & & & 0.23 & $<0.01$ & $0 \cdot 10$ & $<0 \cdot 01$ & $0 \cdot 10$ & $<0.01$ \\
\hline Availability of specific vegetables & & & 0.07 & 0.04 & $<0.01$ & 0.96 & 0.01 & 0.85 \\
\hline Accessibility at home (cut up vegetables to eat between meals) & & & $0 \cdot 16$ & $<0.01$ & 0.06 & 0.08 & 0.05 & $0 \cdot 10$ \\
\hline \multicolumn{9}{|l|}{ Socio-environmental } \\
\hline Modelling (mother eats vegetables every day) & & & & & -0.01 & $0 \cdot 83$ & 0.01 & 0.86 \\
\hline Modelling (father eats vegetables every day) & & & & & 0.05 & 0.23 & 0.03 & 0.44 \\
\hline Modelling (friend eats vegetables every day) & & & & & 0.06 & 0.07 & 0.05 & $0 \cdot 15$ \\
\hline Modelling (eat vegetables together) & & & & & 0.36 & $<0.01$ & 0.35 & $<0.01$ \\
\hline Active encouragement (mother) & & & & & -0.03 & 0.61 & -0.05 & 0.38 \\
\hline Active encouragement (father) & & & & & -0.06 & 0.24 & -0.05 & 0.34 \\
\hline Demand family rule & & & & & $0 \cdot 16$ & $<0.01$ & $0 \cdot 15$ & $<0.01$ \\
\hline Allow family rule & & & & & 0.04 & $0 \cdot 27$ & 0.03 & 0.42 \\
\hline \multicolumn{9}{|l|}{ Personal } \\
\hline Knowledge & & & & & & & $0 \cdot 17$ & $<0.01$ \\
\hline Adjusted $R^{2}$ & 0.085 & & $0 \cdot 195$ & & 0.339 & & 0.366 & \\
\hline$R^{2}$ change & 0.089 & $<0.01$ & $0 \cdot 112$ & $<0.01$ & 0.150 & $<0.01$ & 0.028 & $<0.01$ \\
\hline
\end{tabular}

SES, socio-economic status.

and knowledge of recommendations. The strongest modelling determinant for fruit was the father's fruit intake while for vegetables it was eating vegetables together with the family. The background variables, gender and SES, seemed to be more important determinants of vegetable intake than of fruit intake.

Parents are very likely the most important models for their children; however, there was a low correlation between parent's and child's fruit and vegetable intake. This has been found in other studies, e.g. in a Norwegian study of children of similar age range where the correlation between the children's and their parents' fruit and vegetable intake was $0 \cdot 23^{(13)}$. The low correlations that have been found between food preferences of parents and children have been referred to as the "family para$\operatorname{dox}^{, 22,23)}$. It may indicate that other determinants are 
stronger than parents' intake or preference. A type of family influence that has received increasing research attention in recent years is the influence that parents may have on their children's dietary behaviour through foodrelated parenting practices ${ }^{(11,24)}$. Children may perceive some of the determinants differently from the parents and data obtained both from children and parents make it possible to obtain these 'perceptional biases'.

The Icelandic parents reported greater availability and accessibility of fruits at home than their children. This is consistent with previous studies such as the Norwegian study by Bere and Klepp ${ }^{(13)}$ and the Dutch study by Reinaerts et $a l .{ }^{(15)}$, where parents reported the availability or accessibility of fruits and vegetables as much greater than did their 10-12-year-old children. Reports of children and parents were more in agreement for vegetables, maybe because they are more often eaten as part of meals served by parents. Availability is one of the determinants most consistently related to intake ${ }^{(6,25)}$. In the present study, availability of different kinds of fruits and vegetables at home, as reported by the children, was a significant determinant of intake. Availability may be a more significant determinant of intake where intake is low. A comparison of the nine countries in the Pro Children survey showed that the availability of vegetables was significant for vegetable intake of the Icelandic children, while it was non-significant in the other countries where the intake was higher ${ }^{(26)}$. Comparison of the nine countries in the Pro Children survey showed almost no country differences in the proportion of children reporting fruit to be available at home, except for Icelandic boys, who reported fruit availability to be lower ${ }^{(27)}$. The same tendency, although not significant, was seen for the availability at home of vegetables. Availability at school of both fruit and vegetables was also very low in Iceland. Making fruits and vegetables more easily available to the children might increase their intake, as has been seen in a Norwegian free fruit school programme ${ }^{(28-30)}$.

Children rated their fruit and vegetable intake to be higher than did their parents, and they also reported more often than their parents that eating fruit was a habit for them. This is in line with the Dutch study of 9- to 10-yearold children and their parents by Tak et $a l .{ }^{(14)}$, who too found that children reported significantly higher intake levels of fruits and vegetables than their parents. The Dutch study by Reinaerts et al. ${ }^{(15)}$ also found that children reported higher vegetable intake than their parents; however, fruit intake was similarly reported. Parents of children at that age may not know very well what their children eat as they are at school for a large part of the day, or at clubs, or at friends' houses, and also eat when parents do not see it. From this perspective children's reports of fruit and vegetable intake could be considered more accurate than their parents' reports. The higher intake levels reported by children than by parents in the present study are in contrast with the tentative idea that parents may express more social desirability than children in general. Some previous family studies have found that parents have higher social desirability than children because they may want to demonstrate 'good' parenting resulting in 'healthy' children ${ }^{(31)}$. This pattern of social desirability biases in the responses between parents and children was not found in either the present study or the Dutch studies above ${ }^{(14,15)}$.

Our results on fruit and vegetable intake as well as on the determinants of the intake suggest that self-reports from 11-year-old children should be preferred above reports from their parents. It is necessary to take into account the ability of children of particular ages to report themselves. The development of an instrument has to take children's abilities into account. As Livingstone and Robson argue, from the age of 8 years there is a rapid increase in the ability of children to self-report food intake ${ }^{(32)}$. The accuracy of self-reports in young age groups is highly dependent on the complexity of the instrument used. The instrument used in the present study was developed so that it could be used by 11-yearold children to report themselves without parental assistance ${ }^{(19,21)}$. The reliability of the 100 -item questionnaire was highly acceptable for the Icelandic 11-year-olds, but clearly it might be demanding for younger children ${ }^{(19,21)}$. As Livingstone and Robson suggest, future research should focus on refining dietary survey methods to make them more sensitive to different ages and to look for techniques that are able to identify misreporters ${ }^{(32)}$.

Clear gender differences in fruit and vegetable intake were found, with girls' intake being more frequent than boys'. This is consistent with other European studies ${ }^{(6)}$. Girls also rated their fruit and vegetable intake higher, and they reported more often that eating fruit was a habit for them than did boys. This indicates that the perception children have of their own intake is fairly realistic, as more objective methods also show that girls' intake tends to be higher than that of boys of the same age ${ }^{(33)}$.

Fathers seem to have stronger modelling effects on their children's fruit intake than mothers. Fathers' fruit intake reported by children was positively related to their fruit intake while the mothers' fruit intake, as reported by their children, was non-significant. Studies (mainly answered by mothers) have shown a positive relationship between parents' and children's intake of fruits and vegetables $^{(6)}$. There are few studies on the relationship between fathers' fruit intake and their children's. In an Icelandic study of 6-year-old children and their parents, vitamin $\mathrm{C}$ in blood showed an even stronger correlation between the children and fathers than between the children and mothers ${ }^{(34)}$. It may also be that children eat fruits more often with their father than with their mother and it may therefore be related to eating together. Eating vegetables together as reported by the child was positively related to the child's intake in the present study. Seeing others consume a food may produce a form of 
modelling or 'exposure by proxy' which could reduce rejection and increase acceptance ${ }^{(35)}$.

Children reported more active encouragement and demanding rules from their parents to eat fruit and vegetables daily than did their parents. This may partly be because of a phrasing difference between the child and parent questions. Demand is a strong word, at least in Icelandic, and parents may hesitate to use it. This difference could, however, be partly explained by differences in perception; i.e. the parents do not see themselves as encouraging or demanding as their children do. Active encouragement as reported by parents was negatively related to both fruit and vegetable intake. The parent was asked 'Do you have to persuade your child to eat fruits/ vegetables?' and it is probable that the parents of children with low fruit and vegetable intake are more likely to answer this question positively. Parents of boys reported more encouragement than parents of girls, which seems logical as boys have lower intake levels, and children's low intake might evoke parental encouragement. However, girls and boys reported similar encouragement from their parents. Active encouragement reported by the child was non-significantly related to their fruit and vegetable intake. It is unclear whether active encouragement is an effective way to increase the intake. Children who have low vegetable intake may always have been difficult to feed and, despite a parent's best intention, a child may act with the least desired response from the parent's perspective when it is pressured to eat ${ }^{(11,36)}$. Demanding family rule (reported by a child but not by the parent) seems to be a more effective way to increase intake, as it was positively related to both fruit and vegetable intake. In the cross-Europe survey the association between vegetable intake and demanding family rule was strongest in Iceland and in Norway $(\mathrm{OR}=2 \cdot 1)^{(26)}$. The parents were asked further about the rules regarding vegetables, i.e. if their children were supposed to eat all/part/some of the vegetable with the meal, but none of these was significantly related to children's vegetable intake. Presenting a child with vegetables to taste could be the most promising approach, so that the child tastes vegetables without pressure on how much is eaten. Studies have shown that mere exposure to food increases liking, but attempts to control intake reduce the strength of the exposure effect ${ }^{(36)}$. Wardle et al. suggested that repeatedly inviting children to eat small amounts of rejected or disliked food, without great emphasis on how much the child eats, is a good strategy for promoting the liking of vegetables ${ }^{(37)}$.

Children's knowledge of national recommendations was positively related to their fruit and vegetable intake. The simple strategy of teaching these recommendations in elementary schools may be important to make daily intake more likely ${ }^{(26)}$. Parents' knowledge of recommendations was, however, non-significant, suggesting that parents' knowledge is not enough although it could be the first step, and parents' eating habits and feeding practices are more important determinants of their children's fruit and vegetable intake.

The strength of the present study is the large and representative sample, with a high participation rate. The limitations of the study were that determinants were measured by one item only; however, some of the determinants support each other, e.g. self-rated intake and habit. There may also be a phrasing or semantic difference between the child and parent questions; e.g. in the question on demanding family rule, the parent's question may be more authoritarian than the child's questions. The data are selfreported; therefore, all measures are perceived measures, but thorough validity and reliability studies have shown that the measures were valid and reliable ${ }^{(19,21)}$. As this was a cross-sectional study, it cannot express causality between the determinants and frequency of fruit and vegetable intake.

\section{Conclusion}

The present study shows that children and parents have different perceptions of the determinants of fruit and vegetable intake in a child population with low consumption. Children's perceptions explain more of the variance in intake. Children rather than their parents should be asked what determines their fruit and vegetable intake. However, children reported determinants in the physical and social environment, of which the parents are part, as an important determinant for their intake. Interventions aiming to increase fruit and vegetable intake among children must therefore target the parents. Such interventions ought to focus on practical guidance on how parents can promote healthy food habits.

\section{Acknowledgements}

The authors have no competing interest. All authors are responsible for the reported research. A.G.K. worked on the statistical analysis, wrote the first draft of the manuscript and made the greatest contribution to the paper. K.-I.K. and I.D.B. participated in designing the study and project planning. I.D.B. participated in the data analysis. I.T. was the local project leader and participated in all parts of the work. All authors provided critical revision of the paper, and read and approved the final manuscript. The study was carried out with financial support from the Commission of the European Communities, specifically the RTD programme 'Quality of Life and Management of Living Resources', QLK1-2001-00547 'Promoting and Sustaining Health through Increased Vegetable and Fruit Consumption among European Schoolchildren' (Pro Children). It does not necessarily reflect the views of the RTD programme and in no way anticipates the Commission's future policy in this area. The Pro Children 
consortium consists of the following partners: Knut-Inge Klepp (Coordinator), Department of Nutrition, University of Oslo, Norway; Carmen Perez Rodrigo, Unidad de Nutricion Comunitaria, Bilbao, Spain; Inga Thorsdottir, Unit for Nutrition Research, Landspitali University Hospital, Reykjavik, Iceland; Pernille Due, Department of Social Medicine, University of Copenhagen, Denmark; Maria Daniel Vaz de Almeida, Faculdade de Ciências da Nutrição e Alimentação da Universidade do Porto, Portugal; Ibrahim Elmadfa, Institute of Nutrition, University of Vienna, Austria; Jóhanna Haraldsdóttir, Research Department of Human Nutrition, Royal Veterinary and Agricultural University, Copenhagen, Denmark; Johannes Brug, Erasmus Medical Center Rotterdam, Department of Public Health, The Netherlands; Michael Sjöström, Unit for Preventive Nutrition, Karolinska Institutet, Stockholm, Sweden; Ilse De Bourdeaudhuij, Department of Movement and Sport Sciences, Ghent University, Belgium.

\section{References}

1. Hu FB (2003) Plant-based foods and prevention of cardiovascular disease: an overview. Am J Clin Nutr 78, S544-S551.

2. Key TJ, Allen NE, Spencer EA \& Travis RC (2002) The effect of diet on risk of cancer. Lancet 360, 861-868.

3. Joshipura KJ, Ascherio A, Manson JE, Stampfer MJ, Rimm EB, Speizer FE, Hennekens CH, Spiegelman D \& Willett WC (1999) Fruit and vegetable intake in relation to risk of ischemic stroke. JAMA 282, 1233-1239.

4. World Health Organization (2003) Diet, Nutrition and the Prevention of Chronic Diseases. Report of a Joint WHO/FAO Expert Consultation. Geneva: WHO.

5. Klepp K-I, Perez-Rodrigo C, De Bourdeaudhuij I et al. (2005) Promoting fruit and vegetable consumption among European schoolchildren: rationale, conceptualization and design of the Pro Children project. Ann Nutr Metab 49, 212-220.

6. Rasmussen M, Krolner R, Klepp KI, Lytle L, Brug J, Bere E \& Due P (2006) Determinants of fruit and vegetable consumption among children and adolescents: a review of the literature. Part I: quantitative studies. Int J Behav Nutr Phys Act 3, 22.

7. Lien N, Lytle LA \& Klepp KI (2001) Stability in consumption of fruit, vegetables, and sugary foods in a cohort from age 14 to age 21. Prev Med 33, 217-226.

8. Birch LL \& Fisher JO (1998) Development of eating behaviours among children and adolescents. Pediatrics 101, 539-549.

9. Savage JS, Fisher JO \& Birch LL (2007) Parental influence on eating behavior: conception to adolescence. J Law Med Ethics 35, 22-34.

10. Johnson SL \& Birch LL (1994) Parents' and children's adiposity and eating style. Pediatrics 94, 653-661.

11. Wardle J, Carnell S \& Cooke L (2005) Parental control over feeding and children's fruit and vegetable intake: how are they related? J Am Diet Assoc 105, 227-232.

12. Faith MS, Berkowitz RI, Stallings VA, Kerns J, Storey M \& Stunkard AJ (2004) Parental feeding attitudes and styles and child body mass index: prospective analysis of a geneenvironment interaction. Pediatrics 114, e429-e436.

13. Bere E \& Klepp K-I (2004) Correlates of fruit and vegetable intake among Norwegian school children: parental and self-reports. Public Health Nutr 8, 991-998.
14. Tak NI, te Velde SJ, de Vries JH \& Brug J (2006) Parent and child reports of fruit and vegetable intakes and related family environmental factors show low levels of agreement. J Hum Nutr Diet 19, 275-285.

15. Reinaerts E, de Nooijer J \& de Vries NK (2007) Parental versus child reporting of fruit and vegetable consumption. Int J Behav Nutr Phys Act 4, 33.

16. Yngve A, Wolf A, Poortvliet E et al. (2005) Fruit and vegetable intake in a sample of 11 -year-old children in 9 European countries: the Pro Children cross-sectional survey. Ann Nutr Metab 49, 236-245.

17. Wolf A, Yngve A, Elmadfa I et al. (2005) Fruit and vegetable intake of mothers of 11-year-old children in nine European countries: The Pro Children Cross-sectional Survey. Ann Nutr Metab 49, 246-254.

18. Kristjansdottir AG, Thorsdottir I, De Bourdeaudhuij I, Due P, Wind M \& Klepp KI (2006) Determinants of fruit and vegetable intake among 11-year-old schoolchildren in a country of traditionally low fruit and vegetable consumption. Int J Behav Nutr Phys Act 3, 41.

19. Haraldsdottir J, Thorsdottir I, de Almeida MD, Maes L, Perez Rodrigo C, Elmadfa I \& Frost Andersen L (2005) Validity and reproducibility of a precoded questionnaire to assess fruit and vegetable intake in European 11- to 12-year-old schoolchildren. Ann Nutr Metab 49 , 221-227.

20. Kristjansdottir AG, Andersen LF, Haraldsdottir J, de Almeida MD \& Thorsdottir I (2006) Validity of a questionnaire to assess fruit and vegetable intake in adults. Eur J Clin Nutr 60, 408-415.

21. De Bourdeaudhuij I, Klepp KI, Due P, Rodrigo CP, de Almeida M, Wind M, Krolner R, Sandvik C \& Brug J (2005) Reliability and validity of a questionnaire to measure personal, social and environmental correlates of fruit and vegetable intake in 10-11-year-old children in five European countries. Public Health Nutr 8, 189-200.

22. Rozin P (1991) Family resemblance in food and other domains: the family paradox and the role of parental congruence. Appetite 16, 93-102.

23. Eertmans A, Baeyens F \& Van den Bergh O (2001) Food likes and their relative importance in human eating behavior: review and preliminary suggestions for health promotion. Health Educ Res 16, 443-456.

24. Birch LL \& Fisher JO (2000) Mothers' child-feeding practices influence daughters' eating and weight. $\mathrm{Am} \mathrm{J}$ Clin Nutr 71, 1054-1061.

25. Blanchette L \& Brug J (2005) Determinants of fruit and vegetable consumption among 6-12-year-old children and effective interventions to increase consumption. J Hum Nutr Diet 18, 431-443.

26. De Bourdeaudhuij I, Te Velde S, Brug J et al. (2008) Personal, social and environmental predictors of daily fruit and vegetable intake in 11-year-old children in nine European countries. Eur J Clin Nutr 62, 834-841.

27. Sandvik C, De Bourdeaudhuij I, Due P et al. (2005) Personal, social and environmental factors regarding fruit and vegetable intake among schoolchildren in nine European countries. Ann Nutr Metab 4, 255-266.

28. Bere E, Veierod MB \& Klepp KI (2005) The Norwegian School Fruit Programme: evaluating paid vs. no-cost subscriptions. Prev Med 41, 463-470.

29. Bere E, Veierod MB, Bjelland M \& Klepp KI (2006) Free school fruit - sustained effect 1 year later. Health Educ Res 21, 268-275.

30. Bere E, Veierod MB, Skare O \& Klepp KI (2007) Free school fruit - sustained effect three years later. Int J Behav Nutr Phys Act 4, 5.

31. De Bourdeaudhuij I \& Van Oost P (2000) Personal and family determinants of dietary behaviour in adolescents and their parents. Psychol Health 15, 751-770. 
32. Livingstone MB \& Robson PJ (2000) Measurement of dietary intake in children. Proc Nutr Soc 59, 279-293.

33. Glynn L, Emmett P \& Rogers I, ALSPAC Study Team (2005) Food and nutrient intakes of a population sample of 7-year-old children in the south-west of England in 1999/ 2000 - what difference does gender make? J Hum Nutr Diet 18, 7-19.

34. Thorsdottir I, Gunnarsdottir I, Ingolfsdottir E \& Palson G (2006) Fruit and vegetable intake: vitamin $C$ and $\beta$-carotene intake and serum concentrations in six-year-old children and their parents. Scand J Food Nutr 50, 71-76.
35. Wardle J, Herrera ML, Cooke L \& Gibson EL (2003) Modifying children's food preferences: the effects of exposure and reward on acceptance of an unfamiliar vegetable. Eur J Clin Nutr 57, 341-348.

36. Galloway AT, Fiorito LM, Francis LA \& Birch LL (2006) 'Finish your soup': counterproductive effects of pressuring children to eat on intake and affect. Appetite 46, 318-323.

37. Wardle J, Cooke LJ, Gibson EL, Sapochnik M, Sheiham A \& Lawson M (2003) Increasing children's acceptance of vegetables; a randomized trial of parent-led exposure. Appetite 40, 155-162. 